\title{
Longitudinal study exploring factors associated with neck/shoulder pain at 52 years of age
}

\author{
This article was published in the following Dove Press journal: \\ Journal of Pain Research \\ 24 May 2016 \\ Number of times this article has been viewed
}

\author{
Johanna Hesselman Borg' \\ Maria Westerståhl ${ }^{2}$ \\ Sara Lundell' \\ Guy Madison ${ }^{3}$ \\ Ulrika Aasa' \\ 'Department of Community \\ Medicine and Rehabilitation, Umeå \\ University, Umeå, ${ }^{2}$ Department of \\ Laboratory Medicine, Karolinska \\ Institutet, Stockholm, ${ }^{3}$ Department of \\ Psychology, Umeå University, Umeå, \\ Sweden
}

Objectives: To investigate the ability of work-related measurements, body composition, physical activity, and fitness levels to predict neck/shoulder pain (upper body pain, UBP) at the age of 52 years. Another aim was to investigate the cross-sectional relationships between UBP, work-related factors, and individual factors at the age of 52 years.

Methods: We followed a randomly selected cohort of 429 adolescents that was recruited in 1974 (baseline), when they were 16 years old. The participants completed physical fitness tests, questions about sociodemographic and lifestyle factors at 16, 34, and 52 years of age, and questions about work-related factors and pain in the follow-ups. Logistic regression analyses were used to examine the associations between UBP and the other variables.

Results: Univariate logistic regression analyses showed that high body mass index and the work-related factors, low control, and low social support at the age of 34 years were related to UBP at the age of 52 years. For social support, there was an interaction between men and women where the relationship between low social support and the experience of pain was more evident for women. Among women, body mass index and social support remained significantly related in the multivariate analyses. For men, social support remained significantly related. Cross-sectional relationships at the age of 52 differed from the longitudinal in the sense that measures of joint flexibility and work posture were also significantly associated with UBP.

Conclusion: The fact that the cross-sectional differed from the longitudinal relationships strengthens the importance of performing longitudinal studies when studying factors that might influence the initiation of pain. UBP preventative measures might need to include both lifestyle (such as dietary habits and physical activity to ensure that the individuals are not becoming overweight) and work-related factors such as social support.

Keywords: adolescence, adult, control, demand, physical activity, physical fitness

\section{Introduction}

Most people experience neck/shoulder pain at some point in life. The annual prevalence of neck pain is reported to range from $27 \%$ in Norway to $34 \%$ in the UK and $48 \%$ in Canada. ${ }^{1}$ For shoulder complaints, a systematic review from 2004 showed a range of $7 \%-26 \%$ for point prevalence and $7 \%-67 \%$ for 12 months prevalence. ${ }^{2}$ In the present study we consider upper body pain (UBP) as the expression of these two problems. Many factors have been associated with UBP, the most common ones being work related such as physical or psychosocial factors, and individual factors, such as age, sex, and body dimensions. ${ }^{1,3-7}$ Examples of work-related physical factors are work postures and material handling. Several cohort studies, together with reviews, have shown that heavy physical workload, working in awkward positions, repetitive movement, frequent
Department of Community Medicine and Rehabilitation, Umeå University, SE-90I 87 Umeå, Sweden

Tel +46907869273

Email ulrika.aasa@umu.se
Journal of Pain Research 2016:9 303-310

(c) (1) (8) ( 2016 Hesselman Borg et al. This work is published and liensed by Dove Medical Press Limited. The full terms of this license are available at https:/ www.dovepress. cc. the work you hereby accept the Terms. Non-commercial uses of the work are permitted without any further permission from Dove Medical Press Limited, provided the work is properly attributed. For permission for commercial use of this work, please see paragraphs 4.2 and 5 of our Terms (https://www.doveperess.oom/terms.php).

303
Dovepress

http://dx.doi.org/10.2147/IPR.S93845 
lifting, working with neck flexion, and irregular head and body posture could be risk factors for developing UBP.4-10 Work-related psychosocial factors include measurement of job demands and job control as well as social support at work. Many cohort studies and reviews have shown that low control, high demands, and low levels of supportive leadership and social support at work could be risk factors in developing UBP. ${ }^{4-7,11}$ A 1-year prospective study showed that individuals in jobs with low control were more likely to develop shoulder symptoms, and concluded that control has a larger impact on shoulder pain than demand. ${ }^{12}$

Turning to individual factors, a higher physical activity level can lower the risk of chronic pain in neck/shoulders. ${ }^{13,14}$ However, Kääriä et $\mathrm{al}^{15}$ found no relationship at all between self-reported physical activity level and chronic neck pain, while examining sociodemographic factors, working conditions, lifestyle, and previous pain in the spine. Another individual factor is physical fitness, which refers to "a physiologic state of well-being that allows one to meet demands of daily living or that provides the basis for sport performance, or both". ${ }^{16}$ Physical fitness seems to be similar to physical activity level in its relation to morbidity and mortality ${ }^{16}$ and both muscular and aerobic fitness have shown to be strongly related to decreased low back pain. ${ }^{17}$ In the later study, it was indicated that objectively measured physical fitness might be more strongly related to less low back pain than self-reported physical activity measurements. ${ }^{17}$ Very few longitudinal studies have examined the relationship between physical fitness and the risk of UBP. A systematic review by Hambergvan Reenen et al in 2006 found inconclusive evidence for the relationship between muscle strength and endurance and the risk of UBP, due to the low number of studies. ${ }^{18}$ In addition, Hamberg-van Reenen et al studied these relationships in a large longitudinal study (SMASH). They found an increased risk of UBP in workers who performed poorly when testing for isokinetic neck lifting strength and static endurance of the neck muscles. ${ }^{18}$ A recent Finnish study, however, was unable to predict neck pain from objective measurements of physical fitness (neck muscle strength and passive range of motion). ${ }^{19}$ Regarding anthropometric variables, a longitudinal study by Nilsen et al found that both obesity and overweight in men and women could be predictors for UBP. ${ }^{14}$ This longitudinal finding was supported by a cross-sectional study by Bodin et $\mathrm{al}^{20}$ and a prospective study by Kääriä et $\mathrm{al}^{15}$ both of which showed that overweight and obesity predicted UBP, but only in women.

Since few studies using a longitudinal design have investigated both work-related and individual factors in a general population and have follow-up periods of more than 5 years, the general purpose of this study was to show, which measurements in a life-perspective are related to good upper body health in middle age. The specific aim was to investigate the ability of work-related measurements, body composition, physical activity, and fitness levels at the ages of 16 and 34 years to predict UBP at the age of 52 years. Another aim was to investigate the cross-sectional relationships between UBP, work-related factors, and individual factors at the age of 52 years.

\section{Methods}

We followed a randomly selected cohort of, initially, 429 adolescents, who were recruited to the longitudinal Swedish Physical Activity and Fitness study (SPAF-1958). ${ }^{21}$ The study protocol was in accordance to the Helsinki Declaration of 1975 as revised in 1983 and received ethical approval from the Ethical Board, Umeå, Sweden, Dnr 09-082M. Participation was voluntarily and all participants signed an informed consent form.

\section{Participants and procedure}

This study is one with a longitudinal design that is described in detail elsewhere. ${ }^{21}$ In 1974 (baseline), six geographical areas in Sweden were systematically selected according to climate and population density. One upper secondary school in each area was randomly selected, and from these schools 224 boys and 205 girls in their 1st year (16 years of age) were randomly selected, in order to obtain a representative Swedish sample. ${ }^{22,23}$ In 1992, 65\% of these took part in the follow-up..$^{22,23}$ There were no significant differences between those who took part in the follow-up and the drop-outs, with one exception. Among the men, those who participated had higher marks in physical education (in 1974) than men who did not participate in the 1992 follow-up. ${ }^{22,23}$ In 2010 , a second follow-up was performed inviting all participants, whose addresses could be found, to answer the questionnaire and those still living in the six original areas to participate in testing procedures. ${ }^{21}$ There were some significant differences between those who took part in the follow-up and the dropouts: being a member of a sports club at baseline (16 years of age) was significantly associated with a lower odds for test drop-out at the follow-up for the men. For the women, having a higher value in the 9-minute run test at baseline (16 years of age) was associated with a lower odds for test drop-out at the follow-up (52 years of age). ${ }^{21}$ Figure 1 describes the structure of the follow-ups and the number of participants who answered the questionnaire and performed the physical performance tests. A detailed description of the study population, dropout and test procedure is given elsewhere. ${ }^{21}$ 


\section{A description of the number of participants in the SPAF-1958 cohort study}



Figure I A description of the number of participants in the SPAF-1958 cohort study who answered questionnaires and performed physical performance tests at baseline and two follow-ups.

\section{Measurements}

The cohort participants completed physical fitness tests and answered questionnaires about sociodemographic and lifestyle factors at 16, 34, and 52 years of age, and questionnaires about work-related factors and pain in the two follow-ups $(1992,2010)$. The fitness tests were tested for test-retest reliability in 1974 and/or $1994 .^{22,24,25}$ As a measure of reliability, the correlation coefficient $(r)$ or coefficient of variation were used.

\section{Work-related factors}

In the questionnaires about work-related factors ${ }^{26}$ all questions were assessed through a four-grade scale ranging from never to often. The questions are shown in Supplementary material. Three questions dealt with work-related posture, sixteen questions with work-related psychological factors in accordance with the model by Karasek ${ }^{27}$ (five questions for demand, ${ }^{28}$ six questions for control, ${ }^{28}$ and five questions for work-related social support). ${ }^{26}$ Four indices (posture, demand, control, and social support) were calculated by adding the scores from the answers and dividing the sum by the number of questions (giving a mean value ranging from 1 to 4). Internal consistency for these indices in 2010 showed Chronbach's alpha for posture $(\alpha=0.71)$, control $(\alpha=0.70)$, demand $(\alpha=0.63)$, and social support $(\alpha=0.75)$. For posture, a high value indicates more physical load, for psychological demands, a high value indicates high demands, for control, a high value indicates high control, and for social support a high value indicates high social support.

\section{Physical activity}

At the age of 16 years, the participants answered questions about physical activity. ${ }^{29}$ At the ages of 34 and 52 years, a new standardized questionnaire was used. ${ }^{23,30}$ Information about adult leisure time physical activities was collected regarding type of activity, frequency, and intensity. This information formed the basis for calculating a metabolic equivalent of task (MET)-index, expressed in MET-hours per week. ${ }^{31}$ The questions are shown in Supplementary material.

\section{Physical fitness}

The tests were standardized and the order of the tests was arranged so that they would not interfere with each other. ${ }^{21}$

\section{Aerobic capacity}

In 1974 a 9-minute run test was performed on a $400 \mathrm{~m}$ track where the distance covered in 9 minutes was measured in metres $(\mathrm{r}=0.78 / 0.86) .{ }^{27,32}$ For practical reasons, this test was exchanged for the submaximal cycle ergometer exercise test in 1992 and 2010 to estimate maximal oxygen uptake, $\mathrm{VO} 2 \max (\mathrm{r}=0,88) \cdot{ }^{22,31,33} \mathrm{~A}$ more detailed description of the 
submaximal cycle ergometer exercise test has been presented in earlier articles. ${ }^{22,31}$

\section{Muscular strength and endurance}

In 1974, 1992, and 2010 the two-hand lift test was used to measure maximal static lifting strength $(\mathrm{CV}=10-13) .{ }^{24}$ The subject stood on the dynamometer platform with flexed knees, straight arms, and straight back. Holding a handle connected to a calibrated dynamometer, the participant attempted to lift by extending the legs. Strength was expressed in Newton $(\mathrm{N})$, best of two attempts. ${ }^{21}$ In 1992 and 2010, the curl-up test measured dynamic endurance in abdominal muscles $(r=0,92) .{ }^{24,25}$ The participant was in a supine position with hips and knees flexed $90^{\circ}$ and supported $(\mathrm{r}=0,92) .{ }^{24,25}$ The participant was to curl-up above a stipulated mark on the test mat with hands on opposite shoulders. Number of curl-ups above the mark at a rate of 25 per minute was counted, one attempt. ${ }^{21}$

\section{Balance and flexibility}

To measure balance in 1992 and 2010, the standing balance on one leg test was used $(r=0,90) .{ }^{24,25}$ The participant was to stand on one leg and turn the head from side to side. The time the position was maintained was measured in seconds; best of two trials, the test was stopped after two minutes. ${ }^{21}$ Tests to assess flexibility were used in 1992 and 2010. Lateral flexion of the neck was assessed with the participant in a sitting position, looking straight ahead with back straight, and shoulders stabilized $(r=0,48) .{ }^{25}$ Range of movement of neck flexion, to the right and left, respectively, was measured in degrees with a goniometer. Neck rotation was assessed in the same position $(r=0,74) .{ }^{25}$ Range of movement of rotation to right and left, respectively, was measured in degrees with a goniometer. ${ }^{21}$ Thoracic spine extension was performed in a standing position with straight back $(\mathrm{r}=0,77) .{ }^{25}$ One mark was placed on the seventh neck vertebra $\left(\mathrm{C}^{7}\right)$ and one $30 \mathrm{~cm}$ below. Range of movement was expressed in centimetres as the difference in the distance between the two marks with straight and extended back $(r=0,77) .{ }^{21}$ It was considered important to include balance and flexibility and their aspects of physical fitness in the follow-up studies even if balance and flexibility were not measured at baseline. ${ }^{21}$

\section{Body dimensions}

Anthropometric measurements included height $(\mathrm{cm})$ and weight $(\mathrm{kg})$ and were measured on all three test occasions. Body mass index (BMI) was calculated as body weight per squared body height $\left(\mathrm{kg} \cdot \mathrm{m}^{-2}\right)$.

\section{Upper body pain}

Information on prevalence of symptoms in the neck and shoulder region was obtained through answers to two questions from the standardized Nordic Musculoskeletal Questionnaire: "Have you at any time during the last 7 days had trouble (ache, pain, or discomfort) in your neck?" and "Have you at any time during the last 7 days had trouble (ache, pain, or discomfort) in your shoulders?". ${ }^{26,34}$ These two questions about neck and shoulder pain, respectively, were merged into upper body pain (UBP).

\section{Statistical methods}

Mean and SD for continuous and normally distributed variables, the median and range for nonnormal variables, and percentages for dichotomous variables were used to describe the measurements in the cohort. Sex differences were analyzed using the chi-square tests for dichotomized data and the Student's $t$-test for independent-samples for continuous data. The analyses were performed in SPSS 21.0. All effects were considered significant with a $P$-value $<0.05$. All tests were two-sided. The results from two of the tests were not normally distributed and were therefore transformed for the statistical analyses. The variable BMI was $\lg _{10}$ transformed, and the variable curl up was square root transformed to obtain normally distributed data.

Univariate logistic regression analyses were used to test which of the independent variables were significantly associated with UBP (dependent variable, 1= having UBP at the age of 52 years). Sex was included as an interaction variable together with each of the other variables. Thereafter, multiple logistic regression analysis was performed to investigate which variables could predict UBP at the age of 52 years. Only variables that were significantly associated with UBP in the univariate analyses and that were measured at the ages of 16 and 34 years were included as independent variables in the analysis. All participants who had performed the tests and/or answered the questionnaires were included in the analyses.

\section{Results}

\section{Background characteristics}

Characteristics of the cohort participants who answered the questionnaire and performed the physical fitness tests in $2010(\mathrm{n}=213)$ are presented in Table 1. Approximately $20 \%$ of the cohort participants reported UBP. There were no significant differences between men and women regarding UBP, aerobic capacity, flexibility, balance, or work-related factors. Regarding muscular strength and endurance tests, men had significantly higher results in the two-hand lift and curl-up tests compared to women. 


\section{Relationships between UBP and work- related measurements, body composition, physical activity, and fitness levels}

Longitudinal relationships

Regarding the univariate longitudinal relationships, high BMI and low control at work as well as low social support at the age of 34 were related to UBP at the age of 52 years (Table 2). There was an interaction between sex and social support odds ratio (OR) 5.88, confidence interval (CI) 1.62-21.26, $P=0.007$. Separate analyses for men and women showed that the odds for UBP decreased with high social support at the age of 34 years among women, and that the odds for UBP increased with high social support at the age of 34 years among the men. In the multiple regression analyses where variables that were measured at the ages of 16 and 34 years were included as independent variables, BMI (at 34 years) and social support (at 34 years) remained significantly related to UBP at 52 years (Table 3 ).

Table I Information about prevalence of UBP, sociodemographic variables, METs, physical fitness, and work-related indices for the cohort participants who participated in the second follow-up in 2010

\begin{tabular}{|c|c|c|c|c|}
\hline & Men & $\mathbf{n}$ & Women & $\mathbf{n}^{* * *}$ \\
\hline UBP (\%) & 17 & 159 & 22 & 149 \\
\hline Height $(\mathrm{cm})^{*}$ & $180(7)$ & 112 & $168(6)$ & 98 \\
\hline Weight (kg)* & $87(13)$ & 112 & $72(14)$ & 98 \\
\hline BMI $\left(\mathrm{kg} \times \mathrm{m}^{-2}\right)^{*, \#}$ & $27(23)$ & 112 & $25(25)$ & 98 \\
\hline Smoking (\%) & 5 & 159 & 8 & 148 \\
\hline $\mathrm{MET}^{* *}$ & $71(0-90)$ & 158 & $8(0-124.5)$ & 149 \\
\hline $\begin{array}{l}\text { Aerobic capacity } \\
\left(\mathrm{mL} \times \mathrm{kg}^{-1} \times \mathrm{min}^{-1}\right)^{*}\end{array}$ & $33(8)$ & 100 & $33(11)$ & 87 \\
\hline Two-hand lift $(\mathrm{N})^{* * \#}$ & $\mathrm{I}, 220(252)$ & 106 & 697 (187) & 95 \\
\hline Curl up (No) ${ }^{* *, \#}$ & $36(0-165)$ & 108 & $27(0-379)$ & 94 \\
\hline Balance (s) ${ }^{* *}$ & $59(3-120)$ & 113 & $49(3-120)$ & 97 \\
\hline $\begin{array}{l}\text { Lateral flexion in the } \\
\text { neck right/left }\left({ }^{\circ}\right)^{*}\end{array}$ & $34(7) / 35(7)$ & 112 & $34(7) / 35(7)$ & 98 \\
\hline $\begin{array}{l}\text { Neck rotation } \\
\text { right/left }\left({ }^{\circ}\right)^{*}\end{array}$ & $70(10) / 7 \mid(10)$ & 112 & $71(11) / 70(11)$ & 98 \\
\hline $\begin{array}{l}\text { Thoracic spine } \\
\text { extension }(\mathrm{cm})^{*}\end{array}$ & $2(1)$ & 112 & $2(1)$ & 98 \\
\hline $\begin{array}{l}\text { Posture (higher value - } \\
\text { higher physical load)* }\end{array}$ & $2.7(3.0)$ & 157 & $2.7(3.0)$ & $14 \mid$ \\
\hline $\begin{array}{l}\text { Demand (higher value - } \\
\text { higher demands)* }\end{array}$ & $2.5(3.0)$ & 153 & $2.5(3.0)$ & $14 \mid$ \\
\hline $\begin{array}{l}\text { Control (higher value - } \\
\text { higher control)* }\end{array}$ & $3.2(2.3)$ & 153 & $3.2(2.8)$ & $14 \mid$ \\
\hline $\begin{array}{l}\text { Social support (higher } \\
\text { value - more support)* }\end{array}$ & $3.0(3.0)$ & 152 & $3.2(2.8)$ & 139 \\
\hline
\end{tabular}

Notes: Data are presented as *Mean (SD); **median (range); ***n indicates how many participants were included in each analysis (the questionnaire was sent to 167 men and I 44 women, and I I 4 men and 99 women were invited for testing); \#a significant difference $(P<0.05)$ between men and women.

Abbreviations: BMI, body mass index; MET, metabolic equivalent of task; UBP, upper body pain.

\section{Cross-sectional relationships}

Regarding the cross-sectional relationships, work-related posture, measurements of flexibility in the thoracic spine and neck, at the age of 52 years were related to UBP at the age of 52 years (Table 2). Among the women, having UBP was also related to lower static lifting strength at the age of 52 years ( $P=0.036$ for the interaction between sex and two hand lift strength; Table 2).

\section{Discussion}

Most of the earlier longitudinal studies focusing on why individuals develop UBP have focused either on work-related factors $^{5,7,8,12}$ or on individual factors. ${ }^{13,14,18}$ The SPAF-1958 included measurements of exposure to adverse posture, high psychological demands, low control (decision latitude), and low social support at work at the ages of 34 and 52 years and measurements of physical activity and fitness and body dimensions at ages of 16,34 , and 52 years. In the present study, $17 \%$ of the men and $22 \%$ among the women had ache, pain, or discomfort in the neck and/or shoulder area (UBP) during the last 7 days. These figures corresponds with earlier studies including a point prevalence ranging from $7 \%$ to $26 \%$ for shoulder pain ${ }^{2}$ and an annual prevalence of neck pain in Norway of $27 \%{ }^{1}$ An interesting finding in this study was that low BMI at the age of 34 years was related to good upper body health in middle age. The finding that high BMI at the age of 34 years was associated with pain at 52 years is consistent with earlier research ${ }^{14,15,20}$ showing that overweight and obesity predicts UBP. The effect of BMI might be explained by the metabolic syndrome, which includes atherogenic dyslipidemia, hypertension, glucose intolerance, and a pro-inflammatory state ${ }^{35}$ and might lead to pathological changes within the muscles. Another explanation could be that overweight and obesity might lead to high mechanical load on both the cervical spine and shoulders. A previous study found that individuals with a higher BMI had an increased scapular movement, which could be a compensatory movement to better manage increased arm mass, and this kinematics has also been seen in groups with rotator cuff pathology. ${ }^{36}$

Regarding the work-related variable social support at the age of 34 years, the relationship with UBP at the age of 52 years differed for men and women. Among the women, but not among the men, the odds for UBP decreased when social support index increased (more social support). The fact that the importance of work-related factors differs between men and women is in line with an earlier Swedish cohort study from 2011, which showed a significant interaction between job strain (high demands and low control) and low 
Table 2 Odds ratios (ORs) and $95 \%$ confidence intervals $(\mathrm{Cls})$ for neck/shoulder pain at 52 years

\begin{tabular}{|c|c|c|c|c|c|c|c|c|c|c|c|c|}
\hline & \multicolumn{4}{|c|}{16 years } & \multicolumn{4}{|l|}{34 years } & \multicolumn{4}{|l|}{52 years } \\
\hline & OR & $95 \% \mathrm{Cl}$ & $\mathbf{n}$ & $P$-value & OR & $95 \% \mathrm{Cl}$ & $\mathbf{n}$ & $P$-value & OR & $95 \% \mathrm{Cl}$ & $\mathbf{n}$ & $P$-value \\
\hline Posture & - & - & - & - & 0.71 & $0.42-1.21$ & 232 & 0.209 & 1.92 & $1.13-3.26$ & 298 & 0.015 \\
\hline Psychological demand & - & - & - & - & 0.39 & $0.14-1.08$ & 202 & 0.069 & 1.83 & $0.863-3.90$ & 209 & 0.114 \\
\hline Control & - & - & - & - & 0.20 & $0.06-0.67$ & 203 & 0.009 & 1.59 & $0.67-3.75$ & 209 & 0.282 \\
\hline Social support & - & - & - & - & $\begin{array}{l}2.9 I_{\text {men }} \\
0.50_{\text {women }}\end{array}$ & $\begin{array}{l}0.98-8.70 \\
0.25-0.98\end{array}$ & $\begin{array}{l}118 \\
94\end{array}$ & $\begin{array}{l}0.004 \\
0.042\end{array}$ & 0.74 & $0.4 I-1.36$ & 207 & 0.532 \\
\hline MET (MET-hours per week) & - & - & - & - & 1.06 & $1.00-1.12$ & 290 & 0.069 & 1.00 & $0.98-1.02$ & 305 & 0.994 \\
\hline Aerobic capacity & 1.00 & $1.00-1.00$ & 230 & 0.230 & 1.02 & $0.97-1.06$ & 234 & 0.495 & 0.99 & $0.95-1.03$ & 185 & 0.559 \\
\hline Two-hand lift (N) & 1.01 & $0.99-1.04$ & 300 & 0.230 & 0.99 & $0.96-1.01$ & 230 & 0.279 & $\begin{array}{l}1.00_{\text {men }} \\
0.96_{\text {mome }}\end{array}$ & $\begin{array}{l}0.98-1.00 \\
0.94-0.99\end{array}$ & $\begin{array}{l}105 \\
93\end{array}$ & $\begin{array}{l}0.015 \\
0.036\end{array}$ \\
\hline Curl ups (number) & - & - & - & - & 0.98 & $0.96-1.01$ & 232 & 0.179 & $1.00^{\text {women }}$ & $0.98-1.01$ & 201 & 0.493 \\
\hline Balance (s) & - & - & - & - & 1.00 & $0.99-1.01$ & 234 & 0.883 & 1.00 & $0.99-1.01$ & 208 & 0.299 \\
\hline Lateral flex neck right $\left({ }^{\circ}\right)$ & - & - & - & - & 0.97 & $0.90-1.05$ & 234 & 0.461 & 0.92 & $0.86-0.99$ & 207 & 0.018 \\
\hline Lateral flex neck left $\left(^{\circ}\right)$ & - & - & - & - & 0.98 & $0.92-1.04$ & 234 & 0.525 & 0.94 & $0.89-1.00$ & 207 & 0.063 \\
\hline Neck rotation right $\left({ }^{\circ}\right)$ & - & - & - & - & 1.01 & $0.96-1.06$ & 234 & 0.772 & 0.95 & $0.91-0.99$ & 207 & 0.023 \\
\hline Neck rotation left $\left({ }^{\circ}\right)$ & - & - & - & - & 0.97 & $0.93-1.02$ & 234 & 0.224 & 0.96 & $0.93-1.00$ & 207 & 0.062 \\
\hline Thoracic spine extension $(\mathrm{cm})$ & - & - & - & - & 1.04 & $0.68-1.58$ & 233 & 0.863 & 0.59 & $0.37-0.94$ & 207 & 0.026 \\
\hline BMI (body mass index, $\mathrm{kg} \times \mathrm{m}^{-2}$ ) & 1.14 & $0.98-1.34$ & 307 & 0.100 & 1.20 & $1.04-1.39$ & 234 & 0.015 & 1.07 & $0.97-1.19$ & 207 & 0.165 \\
\hline
\end{tabular}

Notes: aln 1974 test results are measured in meters run $(\mathrm{m})$. In 1992 and 2010 test results are evaluated in estimated maximal oxygen uptake $\left(\mathrm{mL}^{\circ} \times \mathrm{kg}^{-1} \times\right.$ min $\left.^{-1}\right)$. Bold numbers indicate a significant relationship with neck/shoulder pain $(P<0.05)$. For variables where interaction between sex were found, the results are presented separately for men and women. -, no data.

Abbreviation: MET, metabolic equivalent of task.

job support and that this was most evident for women. ${ }^{37}$ Still, regarding other measurements of health, the importance of social support at work might be equally important for men and women. Namely, it was earlier shown that low social support is associated with increased mortality and morbidity in both men and women. This relationship has been explained by the fact that low social support increases stress reactions including a dysregulation of the hypothalamic-pituitaryadrenal axis, which could lead to higher heart rate, higher blood pressure, and higher cortisol levels. ${ }^{38}$

The cross-sectional relationships differed somewhat from the longitudinal relationships. Namely, participants with reported UBP reported higher levels of demanding work positions and had a smaller range of motion in the neck and thoracic spine area. Further, women also presented low per-

Table 3 Odds ratios (ORs) and 95\% confidence intervals (Cls) for UBP. Results from the multiple logistic regression analysis

\begin{tabular}{llll}
\hline $\begin{array}{l}\text { Variables included in the } \\
\text { model }\end{array}$ & OR & $\mathbf{C l}$ & P-value \\
\hline Women & & & \\
$\quad$ BMI, 34 years & $\mathbf{I . 2 9}$ & $\mathbf{I . 0 3 - 1 . 6 5}$ & $\mathbf{0 . 0 2 6}$ \\
$\quad$ Control, 34 years & 0.24 & $0.05-I . I$ & 0.068 \\
$\quad$ Social support, 34 years & $\mathbf{0 . 3 6}$ & $\mathbf{0 . 0 5 3 - 0 . 9 8}$ & $\mathbf{0 . 0 4 7}$ \\
Men & & & \\
$\quad$ BMI, 34 years & 1.01 & $0.8 I-1.24$ & 0.965 \\
$\quad$ Control, 34 years & 0.76 & $0.17-3.4 I$ & 0.722 \\
$\quad$ Social support, 34 years & $\mathbf{3 . 3 0}$ & $\mathbf{I . 0 2 - 1 0 . 7 I}$ & $\mathbf{0 . 0 4 7}$ \\
\hline
\end{tabular}

Note: Bold numbers indicate a significant relationship with UBP $(P<0.05)$.

Abbreviations: BMI, body mass index; UBP, upper body pain. formance in the two-hand lift test. In terms of explanations, we must take seriously the fact that we have no causal effect, which means that confounders are always viable alternatives. For example, it could be that women who experience UBP are more likely to attribute work postures to other agents (ie, "externalize"). Or it could be that some common genetic or other property cause women to experience pain and to have less flexibility or strength. Importantly, the fact that the crosssectional relationships differed from the longitudinal relationships strengthens the importance of performing longitudinal studies when studying factors that might have an influence on the development of pain. Namely, low maximal strength and flexibility might not be important risk factors for, but rather the consequences of, having UBP.

Regular physical activity is associated with a number of physical, psychological, and social health benefits. ${ }^{39}$ We did however not find any significant differences in METs between groups who reported pain and those who did not. The fact that individuals who took part in follow-up 2010 are likely to be more physically active ${ }^{21}$ might have influenced this finding. In other aspects such as adolescent geographical area, school program, body composition, muscular strength, and muscular endurance, the participants in the cohort were, at the second follow-up at the age of 52, still representative of the study cohort. ${ }^{21}$

An important question that arises when we discuss the findings of this cohort study is how these results could influence future interventions to prevent the development of UBP. We conclude that UBP preventative measures might need to 
include both lifestyle (such as dietary habits to ensure that the individuals are not becoming overweight) and work-related factors such as social support. Regarding the finding that the cross-sectional associations differed from the longitudinal associations, it seems obvious that rehabilitation of individuals who have UBP must include measures of physical capacity and flexibility and not only on measures that can prevent UBP. It must however be noted that the tests of flexibility included in the present study were highly standardized and performed similarly on every participant regardless of whether or not they had UBP, or if so, why they had UBP. In some of the cohort participants the decreased neck or thoracic spine flexibility could have been due to decreased joint mobility, whereas in others, it could just have been a nonoptimal movement pattern resulting in decreased range of motion. The finding that participants with UBP experienced a higher physical work load, might be due to the fact that they actually have a higher work load, or that they experience the work load to be higher. In any case, it seems important to adjust the work places of individuals with UBP.

\section{Methodological considerations}

The evaluation of pain is a subjective measurement in this study. In choosing these pain assessments we have made scientific considerations. Katz and Melzack suggest that because pain is subjective, patients' self-reports provide the most valid measure of the experience of pain. ${ }^{40}$ There are several instruments when it comes to evaluating pain. A review from 2002 by Salerno et al presented Nordic Musculoskeletal Questionnaire as one of three tools for measurement identified as most relevant for epidemiologic studies among workers with mild to moderate upper extremity conditions. ${ }^{41}$ From this questionnaire we chose pain during the last 7 days, which we thought was a representative measurement since the last 7 days is close to point prevalence and well represented in people's recollection. But test-retest reliability shows the greatest reliability for life time prevalence and the least reliability for point prevalence. ${ }^{42}$ This may have been a limitation in this study.

\section{Conclusion}

The fact that the cross-sectional relationships differed from the longitudinal relationships strengthens the importance of performing longitudinal studies when studying factors that might influence the initiation of pain. UBP preventative measures might need to include both life-style (such as dietary habits and physical activity to ensure that the individuals are not becoming overweight) and work-related factors such as social support.

\section{Acknowledgments}

The study was supported by grants from the Swedish Research Council for Health, Working Life and Welfare and the Swedish National Centre for Research in Sports. The authors wish to thank Gudrun Hedberg, Jan Kowalski, Margareta Barnekow-Bergkvist, Eva Jansson, all test leaders, and the participants for their contribution to this study.

\section{Disclosure}

The authors report no conflicts of interest in this work.

\section{References}

1. Cote P, van der Velde G, Cassidy JD, et al. The burden and determinants of neck pain in workers: results of the bone and joint decade 2000-2010 task force on neck pain and its associated disorders. J Manipulative Physiol Ther. 2009;32(2 Suppl):S70-S86.

2. Luime JJ, Koes BW, Hendriksen IJ, et al. Prevalence and incidence of shoulder pain in the general population; a systematic review. Scand J Rheumatol. 2004;33(2):73-81.

3. Carroll LJ, Hogg-Johnson S, Cote P, et al. Course and prognostic factors for neck pain in workers: results of the bone and joint decade 2000-2010 task force on neck pain and its associated disorders. Spine. 2008;33(4 Suppl):S93-S100.

4. da Costa BR, Vieira ER. Risk factors for work-related musculoskeletal disorders: a systematic review of recent longitudinal studies. Am J Ind Med. 2010;53(3):285-323.

5. Herin F, Vezina M, Thaon I, Soulat JM, Paris C; ESTEV group. Predictors of chronic shoulder pain after 5 years in a working population. Pain. 2012;153(11):2253-2259.

6. Shanahan EM, Sladek R. Shoulder pain at the workplace. Best Pract Res Clin Rheumatol. 2011;25(1):59-68.

7. Sterud T, Johannessen HA, Tynes T. Work-related psychosocial and mechanical risk factors for neck/shoulder pain: a 3-year follow-up study of the general working population in Norway. Int Arch Occup Environ Health. 2014;87(5):471-481.

8. Eltayeb S, Staal JB, Hassan A, de Bie RA. Work related risk factors for neck, shoulder and arms complaints: a cohort study among Dutch computer office workers. J Occup Rehabil. 2009;19(4):315-322.

9. Mayer J, Kraus T, Ochsmann E. Longitudinal evidence for the association between work-related physical exposures and neck and/or shoulder complaints: a systematic review. Int Arch Occup Environ Health. 2012;85(6):587-603.

10. Hanvold TN, Wærsted M, Mengshoel AM, Bjertness E, Veiersted KB. Work with prolonged arm elevation as a risk factor for shoulder pain: a longitudinal study among young adults. Appl Ergon. 2015;47:43-51.

11. McLean SM, May S, Klaber-Moffett J, Sharp DM, Gardiner E. Risk factors for the onset of non-specific neck pain: a systematic review. J Epidemiol Community Health. 2010;64(7):565-572.

12. Smith CK, Silverstein BA, Fan ZJ, Bao S, Johnson PW. Psychosocial factors and shoulder symptom development among workers. Am J Ind Med. 2009;52(1):57-68.

13. Lahti J, Laaksonen M, Lahelma E, Rahkonen O. The impact of physical activity on physical health functioning - a prospective study among middle-aged employees. Prev Med. 2010;50(5-6):246-250.

14. Nilsen TI, Holtermann A, Mork PJ. Physical exercise, body mass index, and risk of chronic pain in the low back and neck/shoulders: longitudinal data from the Nord-Trondelag Health Study. Am J Epidemiol. 2011;174(3):267-273.

15. Kääriä S, Laaksonen M, Rahkonen O, Lahelma E, Leino-Arjas P. Risk factors of chronic neck pain: a prospective study among middle-aged employees. Eur J Pain. 2012;16(6):911-920.

16. Warburton DE, Nicol CW, Bredin SS. Health benefits of physical activity: the evidence. CMAJ. 2006;174(6):801-809. 
17. Heneweer H, Picavet HS, Staes F, Kiers H, Vanhees L. Physical fitness, rather than self-reported physical activities, is more strongly associated with low back pain: evidence from a working population. Eur Spine J. 2012;21(7):1265-1272.

18. Hamberg-van Reenen HH, Ariens GA, Blatter BM, Twisk JW, van Mechelen W, Bongers PM. Physical capacity in relation to low back, neck, or shoulder pain in a working population. Occup Environ Med. 2006;63(6):371-377.

19. Salo P, Ylinen J, Kautiainen H, Hakkinen K, Hakkinen A. Neck muscle strength and mobility of the cervical spine as predictors of neck pain: a prospective 6-year study. Spine. 2012;37(12):1036-1040.

20. Bodin J, Ha C, Serazin C, et al. Effects of individual and work-related factors on incidence of shoulder pain in a large working population. J Occup Health. 2012;54(4):278-288.

21. Aasa U, Lundell S, Barnekow-Bergkvist M, Jansson E, Westerståhl M. The Swedish physical activity and fitness cohort born in 1958-drop out analysis and overview at 36 years follow-up. Scand J Med Sci Sports. In press 2016.

22. Barnekow-Bergkvist M, Hedberg G, Janlert U, Jansson E. Development of muscular endurance and strength from adolescence to adulthood and level of physical capacity in men and women at the age of 34 years. Scand J Med Sci Sports. 1996;6(3):145-155.

23. Barnekow-Bergkvist M, Hedberg G, Janlert U, Jansson E. Physical activity pattern in men and women at the ages of 16 and 34 and development of physical activity from adolescence to adulthood. Scand J Med Sci Sports. 1996;6(6):359-370.

24. Hedberg G. Utprövning av Styrketest för Skolelever [A try-out of tests of strength for pupils]. National Institute of Occupational Health. Umeå; 1975. Swedish.

25. Bergkvist MHG, Rahm M. Utvärdering av Test för Bedömning av Styrka, Rörlighet och Koordination. [Evaluation of test for assessing strength, flexibility and coordination]. Solna: Arbetsmiljöinstitutet; 1992. Swedish.

26. Barnekow-Bergkvist M, Hedberg GE, Janlert U, Jansson E. Determinants of self-reported neck-shoulder and low back symptoms in a general population. Spine. 1998;23(2):235-243.

27. Karasek R. Job decision latitude, job demands, and cardiovascular disease: a prospective study of Swedish men. Am J Public Health. 1981;71(7):694-705.

28. Chungkham HS, Ingre M, Karasek R, Westerlund H, Theorell T. Factor structure and longitudinal measurement invariance of the demand control support model: an evidence from the Swedish Longitudinal Occupational Survey of Health (SLOSH). PLoS One. 2013;8(8):e70541.
29. Jansson E, Hedberg G. Skeletal muscle fibres in teenagers: relationship to physical performance and physical activity. Scand J Med Sci Sports. $1991 ; 1: 31-44$

30. Bergkvist MHG, Rahm M. Konstruktion och Reliabilitetsprövning av en Enkät för att Kartlägga yrke, hälsa och fysisk aktivitet. [Construction and reliability-testing of a questionnaire evaluating physical activity, health and work-related factors]. Hälsa och Fysisk Aktivitet. Vol 5. Solna: Arbetsmiljöinstitutet; 1992. Swedish.

31. Barnekow-Bergkvist M, Hedberg G, Janlert U, Jansson E. Prediction of physical fitness and physical activity level in adulthood by physical performance and physical activity in adolescence - an 18-year follow-up study. Scand J Med Sci Sports. 1998;8(5 Pt 1):299-308.

32. Hedberg G. Utprövning av ett uthållighetsprov för skolelever [A tryout of a test of endurance for pupils]. Universitet och Lärarhögskolan i Umeå. Pedagogiska rapporter. 1976:48 (English abstract) Swedish.

33. Allen JG, Lomaev O. Physiological fitness of schoolboys. Ergonomics. 1969:12:459-462.

34. Kuorinka IA, Jonsson B, § K. Standard Nordic questionnaires for the analysis of musculoskeletal symptoms. Appl Ergon. 1987(18): 233-237.

35. Kaur J. A comprehensive review on metabolic syndrome. Cardiol Res Pract. 2014;2014:943162.

36. Gupta M, Dashottar A, Borstad JD. Scapula kinematics differ by body mass index. J Appl Biomechan. 2013;29(4):380-385.

37. Lindeberg SI, Rosvall M, Choi B, et al. Psychosocial working conditions and exhaustion in a working population sample of Swedish middle-aged men and women. Eur J Public Health. 2011;21(2):190-196.

38. Ozbay F, Johnson DC, Dimoulas E, Morgan CA, Charney D, Southwick S. Social support and resilience to stress: from neurobiology to clinical practice. Psychiatry. 2007;4(5):35-40.

39. Reiner M, Niermann C, Jekauc D, Woll A. Long-term health benefits of physical activity - a systematic review of longitudinal studies. $B M C$ Public Health. 2013;13:813.

40. Katz J, Melzack R. Measurement of pain. Anesthesiol Clin North America. 1992(10):229-246.

41. Salerno DF, Copley-Merriman C, Taylor TN, Shinogle J, Schulz RM. A review of functional status measures for workers with upper extremity disorders. Occup Environ Med. 2002;59(10):664-670.

42. Dawson AP, Steele EJ, Hodges PW, Stewart S. Development and testretest reliability of an extended version of the Nordic Musculoskeletal Questionnaire (NMQ-E): a screening instrument for musculoskeletal pain. J Pain. 2009;10(5):517-526.
Journal of Pain Research

\section{Publish your work in this journal}

The Journal of Pain Research is an international, peer-reviewed, open access, online journal that welcomes laboratory and clinical findings in the fields of pain research and the prevention and management of pain. Original research, reviews, symposium reports, hypothesis formation and commentaries are all considered for publication.

\section{Dovepress}

The manuscript management system is completely online and includes a very quick and fair peer-review system, which is all easy to use. Visit http://www.dovepress.com/testimonials.php to read real quotes from published authors. 